\title{
Video Lessons via YouTube Channel as Mathematics Interventions in Modular Distance Learning
}

\author{
Alvin Odon Insorio ${ }^{1,2,3 *}$ (), Daniel Manansala Macandog 3,4 (])
}

${ }^{1}$ College of Graduate Studies and Teacher Education Research-Philippine Normal University, PHILIPPINES

${ }^{2}$ San Pedro College of Business Administration, PHILIPPINES

${ }^{3}$ San Pedro Relocation Center National High School - Main Campus, PHILIPPINES

${ }^{4}$ Polytechnic University of the Philippines - San Pedro Campus, PHILIPPINES

*Corresponding Author: alvininsorio0413@gmail.com

Citation: Insorio, A. O., \& Macandog, D. M. (2022). Video Lessons via YouTube Channel as Mathematics Interventions in Modular Distance Learning. Contemporary Mathematics and Science Education, 3(1), ep22001. https://doi.org/10.30935/conmaths/11468

\begin{abstract}
Modular distance learning is a new learning delivery modality implemented by most public schools in the Philippines. However, as seen on the summative test result for the first grading period, students struggled in Grade 7 Mathematics using the self-learning modules. Hence, mathematics concepts were hard to understand and not explained well in the module. To address the problem, the teacher made video lessons and uploaded them to the YouTube channel Direct to the Point by DM as interventions. A YouTube channel as an avenue to upload educational videos has been used before the pandemic. This platform's advent can be used in delivering mathematics interventions since the students preferred to watch videos. This study aimed to assess the Mathematics video lessons via a YouTube channel for modular distance learning. This was a practical action research design following the PDSA model that utilized the participants' pretest and the posttest scores. Also, open-ended surveys and interviews were conducted to elicit qualitative data to support the quantitative findings. The result reveals that video lessons help the students understand the mathematics concepts complementing lessons on the modules. Moreover, they enjoyed watching the teacher-made videos since they see the teacher explaining the lesson. However, the students suggested having regular posting of videos with more examples and explanations having clear and loud voice of the teacher.
\end{abstract}

Keywords: mathematics interventions, modular distance learning modality, video lessons, YouTube

Received: 14 May $2021 \bullet$ Accepted: 28 Oct. 2021

\section{INTRODUCTION}

In the Philippines, modular distance learning is the most implemented distance learning modality in public schools, which means the students learn through printed or digital self-learning modules as most preferred by the parents (Bernardo, 2020). The teacher may assist the students via text, email, call, or instant messaging platforms in this modality. However, the immediate response of the teacher is not always possible due to an unstable internet connection. Teachers shall visit the students at home who need remediation and assistance, but because the COVID-19 is contagious, this is not possible in the local context. Moreover, it is the teacher's responsibility to regularly monitor the learner's progress via any means (Depertmant of Education, 2020). The printed modules are given to parents, guardians, or students by assigned teachers or with the help of barangay officials. Instructions on what activities to be done are given through communication means like social media or text weekly. It connotes that teachers must find a way to reach the students through any means as long as the health protocols are properly observed.
Through modules, students are encouraged to do an independent study. However, most students are not capable of studying independently (Dangle \& Sumaoang, 2020). They cannot easily follow the instruction written in the modules, and concepts are hard to understand without teachers' assistance. Moreover, students need constant motivation and reinforcement to pursue self-learning from teachers. It means students are not capable of learning autonomously; they need much assistance from teachers. Thus, the students' outputs from the activities in the modules were submitted late and mostly incomplete, which was not expected from them.

Moreover, topics were not simplified, and fewer examples were found in the modules. To address these challenges, the teacher must place appropriate interventions that need to be given to the struggling students like coherent consultation via call, text, and social media platforms, simplify the module and give immediate feedback on the student's outputs (Dangle \& Sumaoang, 2020). To improve modular distance learning, students suggested reducing the learning activities taken from the modules, giving more examples for each lesson, doing home visitation, providing colorful-printed modules, and giving immediate feedback from the teachers. Moreover, teachers may do 
online consultations, use social media platforms, and have enough time to accomplish the task. The most feasible is utilizing social media since most of the students have access to this, and face-to-face interaction is not permitted. Researchers believe that the module alone can not explain the mathematical concepts and develop the students' learning competencies. There should be interventions to be done by the teachers utilizing the available resources and based on the students' learning needs.

\section{LITERATURE REVIEW}

The students' smartphones and portable devices are rapidly increasing for the past years (Benedict \& Pence, 2012; Ranga, 2017; Williams \& Pence, 2011). As a result, students are overwhelmed by many online applications that can be used for learning school subjects. However, finding relevant online resources is a challenge for them to choose the most aligned learning materials taught in school. To address this, the teacher may create a customized lesson in videos or digital materials to use them as a replacement for face-to-face discussion, especially when distance learning happens. Customized videos can be upload to the YouTube channel as a platform that the students may consume anytime and anywhere. Ranga (2017) enumerated the benefits of a customized video via YouTube, such as students having learning ownership, utilizing self-paced learning, watching the video repeatedly, and providing a platform for reviewing the lesson. These empower the students to become responsible for their learning through devices as a ubiquitous opportunity.

YouTube as a meaningful learning resource for students to keep in learning anytime with little cost may be used by teachers as a tool for the teaching-learning process to enhance knowledge acquisition and develop skills (Clifton \& Mann, 2011; Copper \& Semich, 2019). It facilitates learning by increasing the interest of students in school subjects (Buzzetto-More, 2014; DeWitt et al., 2013), enhances the content understanding of a lesson (Clifton \& Mann, 2011), and encourage self-directed learning (Lee et al., 2017). Also, it provides a distinct learning environment that enables social interaction wherein users can upload, view, share, and post comments on educational videos, besides it allows to communicate with a video contributor to create an interactive online learning group (Jung \& Lee, 2015; Lee et al., 2017). Furthermore, YouTube provides a learning pace to the students since they can pause, fast-forward or replay the video anytime and anywhere as long as the device is connected to the internet (Hong et al., 2016) since it is $24 / 7$ available online. Moreover, using YouTube is cheap, which can be used by the teacher in delivering online lectures as an alternative for face-to-face teaching (Subhi et al., 2020). The statements above justify that the teacher can use the YouTube video to deliver the lesson accessible for the students with an internet connection for distance learning.

June et al. (2014) found that YouTube videos are exciting, fun, and may increase the students' engagement and participation and enhance critical thinking skills. Youtube videos cater to various learning styles, whether the student is kinesthetic, auditory, or visual since they have a sense of attraction such as graphics, sounds, and colors (Vural, 2013). The students participate actively and show interest in learning since they can understand the lesson better through watching the teacher lecturing the lesson. Through YouTube videos and supporting activities, students formulate ideas in solving problems and induce critical thinking skills to collaborate towards the problem (Taylor \& Parsons, 2011).

Muniyandy et al. (2015) incorporated YouTube videos as teaching materials in their study. They found a significant learning improvement happens mainly if an explanation about the video is included. This supported the study of Tan and Pearce (2011), who found out that YouTube is an effective and valid platform to support and enhance students' learning when used if further explanation about the content of videos is given to the students. It means that the video must be made by the teacher of the student-consumers explaining the lesson's content suited to the student's level of understanding. Furthermore, the learning content in the video lesson must be explained thoroughly by the teacher to learn the target competencies embedded in the lesson quickly.

Moghavvemi et al. (2018) argued that YouTube videos as supplementary learning resources enhanced the learning experience if pertinent videos are utilized for teaching school subjects. So, it means that videos must be related to the lesson in school subjects to feel the urgency of watching the video. Zhou et al. (2020) concluded that the students are preferred to use YouTube as a source of learning if they expected to earn positive outcomes relevant to school learning. This justifies that the educational videos must be aligned with school lessons to motivate the students to pay attention to watch them. Moreover, the video lessons must be based on the curriculum taught in school to feel the need to consume them. Specifically, in this new normal, video lessons must be introduced as supplementary materials for modular learning that make the learning more engaging (Bullo, 2021).

\section{Conceptual Framework}

Grade 7 Mathematics is a part of the secondary education curriculum in Philippine Basic Education consists of topics from Algebra, Geometry, and Statistics which serves as a transition from elementary mathematics education to the secondary level. By considering the result of the first quarter summative test from San Pedro Relocation Center National High School - Main Campus, it has been observed that the students are struggling in the mathematics lessons. This was probably due to the modular distance learning modality implemented for the school year 2020-2021, wherein selflearning modules were given to replace teachers. To address the problem, an initial survey was conducted to reveal the reasons. It was found that modules were not simple to understand, fewer examples were given per lesson, and instructions in the activities were not clear. However, $90 \%$ of the students have internet access via data load or fiber connection and devices that can be used for communication. So, mathematics teachers found ways to help the Grade 7 students understand the lesson appropriate to their understanding level through an online resource.

Considering the students' interest in watching videos via YouTube, the study utilized this platform to create a channel named Direct to the Point by DM as an avenue to upload the teacher-made video lessons weekly. This was aligned to the most essential learning competencies (MELC) prescribed by the Department of Education (DepEd). Weekly video lessons were uploaded by the mathematics teacher with a span of fewer than 30 minutes and activity right after the video to verify that the students consumed the video. It was believed that digital interventions positively affect the acquisition of competencies in mathematics for secondary students (Bokhove \& Drijvers, 2012). 
The study was carried on in San Pedro Relocation Center National High School - Main campus for the school year 2020-2021, located at Old Tenant Imelda Avenue Langgam, San Pedro City, Laguna Philippines. It is a public school offering junior and senior high school catering 5,800 students under a modular distance learning modality. Also, it is committed to delivering quality and accessible education despite the pandemic's challenges through a school learning continuity plan. Furthermore, the said school prioritizes students, teachers, and staff's welfare, health, safety, and well-being and strives to continue delivering quality basic education.

The study utilized the Youtube Channel Direct to the Point by DM to deliver mathematics video lessons as interventions for Grade 7 for modular distance learning. Weekly MELC-aligned teacher-made video lessons were uploaded to the Youtube channel so that the students watch anytime in the comfort of their houses. Instructions to the students were given to verify if they watch the video, like posting comments, thumbs up, or subscribe, and a follow-up activity was given after every video. There were appropriate and timely monitoring and feedback for the interventions done by the mathematics teachers weekly to ensure that the students use the interventions. Also, Youtube provides analytics as a tool to trace easily all received and viewed videos and post comments which helps the teacher monitor the number of video consumers (Terlumun et al., 2018). This may ensure that the students watch the video lessons by clicking the view button. The teachers utilized data analytics from YouTube to determine if they consume uploaded videos as part of monitoring.

Figure 1 exhibits the flow of the study under the PDSA model. The planning stage started with the mathematics teachers' meeting about the students' challenges under modular distance learning and possible interventions. After the meeting, permission from the school head was secured to conduct the study by administering an initial survey to elicit grounded data regarding the students' challenges and their available resources to establish the technological capability. Sequentially, a pretest material was constructed and validated by experts in mathematics education to measure the students' prior knowledge. Under the do stage, the intervention was pilot tested on nonparticipants for two weeks to determine its feasibility. Based on the result, the intervention was possible to administer, and key learning was considered for the implementation. After that, a pretest was

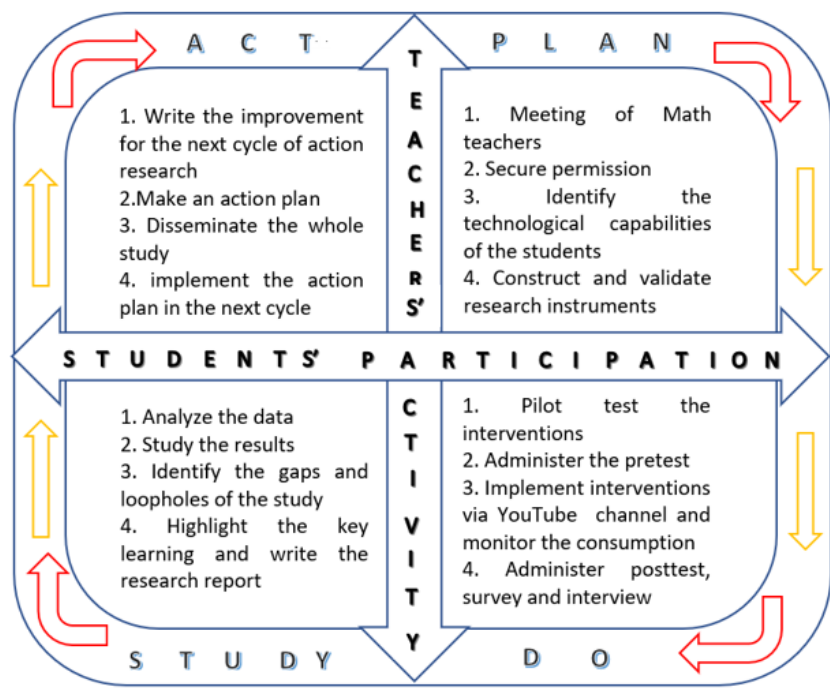

Figure 1. Conceptual paradigm administered to the participants via a google form wherein the link was posted on the YouTube channel for one week, and each student may answer it once. If the students do not have a data load for internet access, they messaged the teacher so that the data load was given to them. The result was kept confidential for future use. Two months of interventions were employed by posting video lessons via the YouTube channel Direct to the Point by DM. Communication with the students to notify them about the uploaded video lesson was done through the Messenger groups. After that, the posttest was administered to measure the learning outcomes via Google form. Surveys via Google form and interviews via calls were conducted to elicit qualitative data to support the quantitative findings.

For the study stage, quantitative data were treated statistically, while qualitative data were treated through thematic analysis. The results were studied carefully to identify the gaps and critical learning for improvement on the next cycle of action research. On the Act stage, an action plan was crafted considering improvements and plans. Finally, dissemination of results was done through learning action cell, conferences, and hopefully publish in an international journal.

\section{Research Questions}

This study aimed to assess the use of the YouTube channel Direct to the Point by DM as a platform to deliver the teacher-made video lesson interventions for modular distance learning modality. Specifically, it answered the following questions:

1. What are the mean scores of students in the pretest and the posttest examination?

2. Is there a significant difference in the mean scores of pretest and posttest?

3. How do the teacher-made video lessons via YouTube channel help the student understand the mathematics lesson better?

4. What will the students' suggestions to improve the video lessons posted on the YouTube channel?

\section{METHODOLOGY}

\section{Research Design}

The study applied a practical action design focusing on utilizing the YouTube channel in delivering Mathematics video lessons for modular distance learning modality in Grade 7 Mathematics. The said design was the most appropriate to apply since the study's main goal was to solve the immediate learning problem perceived from modular distance learning. Fraenkel and Wallen (2010) characterized practical action research as a design intended to solve a certain problem in improving practitioners' practices utilizing the available resources. This type of research is commonly used to address issues, concerns, and challenges experienced in the local context of practitioners for a short term, applying appropriate intervention, innovation, or change in practice.

\section{Participants of the Study}

The participants were from four sections with a total of 110 students who have the least mastered learning competencies in the first grading period. These students struggled in mathematics due to a modular distance learning modality wherein they learn independently with less assistance from the teacher. As seen on their submitted 


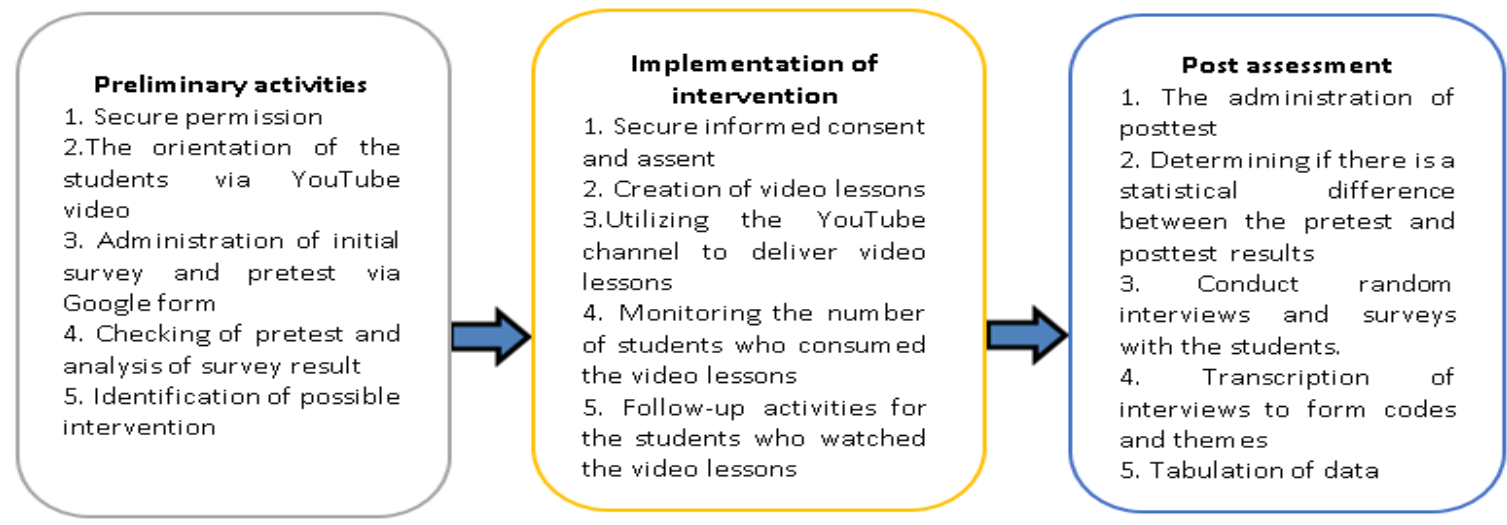

Figure 2. Flow chart of data gathering procedure in three stages

outputs from the summative test and performance task, they did not perform well. Many of them got low scores or did not submit complete outputs. So, the teacher crafted interventions via YouTube to help them to develop the target learning competencies. It seemed that self-paced learning is not effective alone through the use of modules. There should be teacher interventions so that the students learned the mathematics lessons correctly.

Moreover, the module for the third grading period was not provided early by DepEd authorities, so late distribution was carried on. Hence, strict community quarantine was implemented wherein students could not go outside their houses to get learning materials provided by the teacher to replace the self-learning modules for a while. Only their parents could get the said modules in school for one day following strictly the protocol seemly implemented by school officials. To address the challenge, video lessons were crafted by the teacher to continue learning even the students were staying at home.

\section{Research Instruments}

The study's research instruments were test materials, an openended survey questionnaire, and interview guide questions were authenticated by the two master teachers and a head teacher regarding format, design, usefulness, content, and clarity to establish the content and face validity. The suggestions of the validators were strictly followed such as grammar issues, proper use of punctuation marks, alignment of the items on curriculum objectives, and sequencing of items. Then, the instruments were revised twice before their use. The validators rated the second-revised instruments suitable for the study. The 30-item test material for pretest and another 30-item test material for posttest was administered to measure the learning outcome due to teacher-made video lessons. First, pilot testing of the test materials was done as part of pre-implementation to non-participants to determine the reliability using Kuder-Richardson Formula 20. As a result of the pilot testing, test materials have .82 and .85 reliability indices, respectively. Then, two-month implementation period was considered in the study, and after that, a posttest was administered via Google form.

In the final test material as a result of item analysis, 3 items were found between 0.20-0.39 difficulty index, 9 items were found between 0.40-0.59 difficulty index, and 18 items were found between 0.60-0.79 difficulty index. The said test instrument was composed of $60 \%$ easy, $30 \%$ average, and $10 \%$ difficult. For the discrimination index, 5 items were found in the range of $0.30-0.39$, while 25 items were found more than 0.40 . It means the items were discriminating and good. Also, there were 4 items with $66.66 \%$ and 26 items with $100 \%$ for distractor efficiency. The quality of test materials administered to the students can be established through item analysis (Sharma, 2021). Moreover, a fiveitem open-ended survey questionnaire and five-item interview questions were administered to elicit qualitative data regarding the effect of watching video lessons on students' academic performance in mathematics and suggestions for improvement.

\section{Data Gathering Methods}

Figure 2 shows how the methodological processes were done in this study, from pre-implementation to post-implementation. First, permission from the school head was secured by writing a formal letter signed by the Mathematics department head as part of the protocol. After the grant of permission, orientation with the students was held to inform the study's procedure via video. Next, an initial survey was administered to determine the students' challenges in modular learning and technological capabilities regarding device ownership and internet connections to put considerations and adjustments on priorities. Similarly, a 30-item pretest was administered via Google form for one week by posting the link. Finally, if the students do not have internet access, they may message the teacher to give a data load on that day. The teacher kept the results, and data analysis from the initial survey was done immediately.

From the initial survey results, the researchers identified the possible interventions considering the availability of resources, technological capabilities of the students, the module's content, most essential learning competencies, and nature of learners. They crafted a mechanism on how to create and implement the interventions. Interventions in video lessons, follow-up activities, and the surveys link were posted via the YouTube channel Direct to the Point by DM. Before the implementation stage, the informed consent and assent form was sent to the students during the module's distribution since the participants were minors between the age of 12 to 15 years old. The student's voluntary participation was considered for inclusion as participants.

The interventions were implemented for two months under the 3rd grading period via the YouTube channel. The mathematics teacher monitored video consumption to identify the number of students who consumed the interventions. Instructions of the follow-up activities were given, and the students must answer the activities as proof of consuming interventions. The answer to the activities was sent through a personal message to avoid leakage or cheating. A posttest was administered after two months to assess the learning outcomes by identifying significant differences in pretest and posttest scores. Surveys 
Table 1. One-sample Kolmogorov-Smirnov test for normality of data

\begin{tabular}{|c|c|c|c|c|c|c|c|c|c|}
\hline \multicolumn{2}{|c|}{ Statistics } & \multicolumn{4}{|c|}{ Pretest } & \multicolumn{4}{|c|}{ Posttest } \\
\hline & & A & $\mathrm{B}$ & $\mathrm{C}$ & $\mathrm{D}$ & $\mathrm{A}$ & $\mathrm{B}$ & $\mathrm{C}$ & $\mathrm{D}$ \\
\hline $\mathrm{N}$ & & 30 & 30 & 30 & 20 & 30 & 30 & 30 & 20 \\
\hline \multirow{2}{*}{ Normal parameters ${ }^{\mathrm{a}, \mathrm{b}}$} & Mean & 12.33 & 9.80 & 9.83 & 9.10 & 24.46 & 24.03 & 24.77 & 24.75 \\
\hline & Std. Deviation & 3.689 & 3.178 & 3.030 & 2.490 & 2.430 & 2.798 & 2.096 & 1.860 \\
\hline \multirow{2}{*}{$\begin{array}{c}\text { Most extreme } \\
\text { differences }\end{array}$} & Absolute & .108 & .099 & .145 & .100 & .131 & .102 & .122 & .157 \\
\hline & Positive & .074 & .099 & .145 & .100 & .073 & .092 & .078 & .157 \\
\hline \multicolumn{2}{|c|}{ Test statistic } & .108 & .099 & .145 & .100 & .131 & .102 & .122 & .157 \\
\hline \multicolumn{2}{|c|}{ Asymp. Sig. (2-tailed) } & $.200^{\mathrm{c}, \mathrm{d}}$ & $.200^{\mathrm{c}, \mathrm{d}}$ & $.110^{\mathrm{c}}$ & $.200^{\mathrm{c}, \mathrm{d}}$ & $.134^{\mathrm{c}}$ & $.200^{\mathrm{c}, \mathrm{d}}$ & $.200^{\mathrm{c}, \mathrm{d}}$ & $.200^{\mathrm{c}, \mathrm{d}}$ \\
\hline
\end{tabular}

Table 2. Mean, standard deviation, and effect size of pretest and posttest scores

\begin{tabular}{|c|c|c|c|c|c|c|c|}
\hline & Minimum value & Maximum value & Mean & SD & Mean difference & Cohen's d & Percentage change \\
\hline Pretest & 4 & 19 & 10.37 & 3.37 & -14.08 & 4.18 & 136.78 \\
\hline Posttest & 19 & 29 & 24.45 & 2.39 & & & \\
\hline
\end{tabular}

were conducted to determine the effect of interventions and students suggestions regarding the interventions. Random interviews were conducted to verify and clarify the students' responses to the survey.

\section{Ethical Considerations}

As part of the ethical considerations, monetization of the video was turned off since the intervention's focus was to reach and help the students. Moreover, the data confidentiality and identity of the participants were treated with the utmost secrecy to protect them from harm. Codes were used to represent the students to cover their identities from the data collection up to dissemination. Parental consent was secured before the implementation process. The participants were informed that the data gathered from this study were stored securely on the researchers' personal computer for three years, after which all participants' identities will be erased. Furthermore, the study's findings were disseminated to the faculty through meetings and a learning action cell, hoping for benchmarking to other subjects.

\section{Data Analysis}

Quantitative data were treated using mean, standard deviation, one-sample Kolmogorov-Smirnov test, paired sample t-test, Cohen's d, and percentage change to answer the first two research questions using SPSS version 23. For qualitative data, codes were assigned in the interview transcripts after reading and reading again manually. Thematic analysis was used to arrive at themes derived from the categories of codes. Given (2008) defined thematic analysis as reducing qualitative data to search for patterns of experience just to show descriptions known as themes. After qualitative data analysis, the transcript and themes were returned to the participants and they were asked to check the completeness and accuracy of their qualitative responses to establish member checking. The participant's validation was highly followed and the transcript was modified based on their corrections to ensure that the true responses were reflected on the data. The researcher believed that quantitative findings were not enough to assess the effectiveness of interventions, so qualitative findings will complement.

Table 1 depicts the normality test of the distributions of scores from the pretest and the posttest. Using a one-sample Kolmogorov-Smirnov (KS) test, scores were normally distributed since the p-values were more than the .05 significance level. Soong (2004) insisted that if the computed value of the KS test is greater than the .05 significance level, then the data set resembles a normal probability distribution. This permits the use of a parametric test, specifically a t-test for paired samples for the significant difference before and after treatment. The KS test is a commonly used test for the normality of data before the use of any parametric test (Pallant, 2007). Furthermore, Okeniyi et al. (2015) asserted the normality of data must be established first before any inferential statistical test and also as part of describing the quantitative data. Hence, the normality of the distribution of numerical data must be established first before using a parametric test (Broto, 2008). So, it is a must to test the normality of numerical data before doing further statistical analysis. Moreover, considering the mean scores in pretest, section $\mathrm{D}$ got the lowest pretest mean, while section A got the highest. Unlikely, section B got the lowest posttest mean, while section $\mathrm{C}$ got the highest in posttest. Thus, the score increment from the pretest to the posttest signifies that the students' performance increased due to YouTube videos as supplementary materials that promote the learning experience (Moghavvemi et al., 2018).

\section{RESULTS}

Table 2 displays the mean, standard deviation, and effect size of the pretest and posttest scores. Mean is most often used measure for central tendency while the standard deviation is for variability for quantitative data prelude to the normality test (Lydersen, 2020). Since scores were measured quantitatively, then the mean and the standard deviation are the two appropriate descriptive measures. The pretest scores range from 4 to 19 while the posttest scores range from 19 to 29 . The table shows that the posttest mean score is higher than the pretest mean score. The increase of mean score signifies that video lessons via the YouTube channel improve the academic performance in the examination which is similar to the findings of Farhan (2019). A YouTube channel as a platform to deliver video lessons helped the students to understand the mathematics lessons conveniently.

Hence, the effect size using Cohen's $d$ which is 4.18 means that the posttest scores are higher than the standard deviation of the pretest scores which means interventions affect the students' academic performance. It implies that a high effect size denotes effective interventions that must be employed again. It connotes that the interventions via YouTube channel affect the academic performance of the students in mathematics since Cohen's d is commonly applied to calculate the effect size of interventions for the pretest and the posttest scores of the same group to establish the practical significance (Dankel 
Table 3. Paired samples t-test for significant difference

\begin{tabular}{|c|c|c|c|c|c|c|c|c|c|}
\hline & \multirow{3}{*}{ Pairs } & \multicolumn{5}{|c|}{ Paired differences } & \multirow{3}{*}{$\mathbf{t}$} & \multirow{3}{*}{ df } & \multirow{3}{*}{$\begin{array}{l}\text { Sig. }(2- \\
\text { tailed) }\end{array}$} \\
\hline & & \multirow{2}{*}{ Mean } & \multirow{2}{*}{ SD } & \multirow{2}{*}{$\begin{array}{c}\text { Std. error } \\
\text { mean }\end{array}$} & \multicolumn{2}{|c|}{$95 \%$ confidence interval of the difference } & & & \\
\hline & & & & & Lower & Upper & & & \\
\hline Pair 1 & Pretest A - Posttest A & -11.450 & 4.273 & .956 & -13.450 & -9.450 & -11.983 & 29 & .000 \\
\hline Pair 2 & Pretest B - Posttest B & -14.800 & 3.427 & .766 & -16.404 & -13.196 & -19.311 & 29 & .000 \\
\hline Pair 3 & Pretest C - Posttest C & -15.550 & 3.706 & .829 & -17.284 & -13.816 & -18.765 & 29 & .000 \\
\hline Pair 4 & Pretest D - Posttest D & -15.650 & 2.661 & .595 & -16.895 & -14.405 & -26.301 & 29 & .000 \\
\hline
\end{tabular}

et al., 2017). In addition, the percentage change of 136.78 signifies the magnitude of the effect of the interventions derived from the formula of the difference between the pretest and the posttest scores divided by the pretest score times one hundred (Clark et al., 2010; Hansen et al., 2011). It tells the strength of the effect of the interventions. This justifies the cause of score increment was due to interventions. Furthermore, Cohen's $d$ and percentage change are the two measures of the magnitude of the effect as a result of interventions (de Villarreal et al., 2009, 2010).

Table 3 shows that a significant difference exists between the pretest and the posttest mean scores. The p-values are lower than the .05 significance level at the degree of freedom of 29. It means that interventions via a YouTube channel helped the students to perform better academically. Since the teacher explained the lesson content in the video lessons, the students had significant learning improvement from the test result similar to the findings of Muniyandy et al. (2015). Furthermore, it implies that the YouTube channel can deliver video lessons and activities that help the students understand the mathematics concepts.

Moreover, considering the mean difference, section D got the highest increment from pretest to posttest results. The negative result means the posttest scores are higher than the pretest, which is the manifestation of a good result of interventions. The YouTube video lessons increased the students' understanding of mathematics lessons (Clitton \& Mann, 2011). Moreover, Youtube empowered the students to watch the video lessons on their control since they can replay or pause anywhere and anytime as long as their devices have internet access (Hong et al., 2016).

Figure 3 shows the effects of teacher-made video lessons via YouTube on the Grade 7 students. Students understood the math lesson well through video lessons since their teacher explains the lesson in a bilingual manner - Filipino and English. In addition, they became confident to answer the activities assigned to them from their module because they were guided on how to deal with them. Moreover, they developed techniques to deal with mathematical problems integrated into the module activities. This implies that the students were likely to consume video lessons to produce positive outcomes relevant to the school subject which supports the study of Zhou et al. (2020). The content of the video lessons was aligned to the target competencies in school, so the students were urged to consume them. Video lessons as digital interventions helped students acquire the mathematics competencies of secondary students (Bokhove \& Drijvers, 2012).

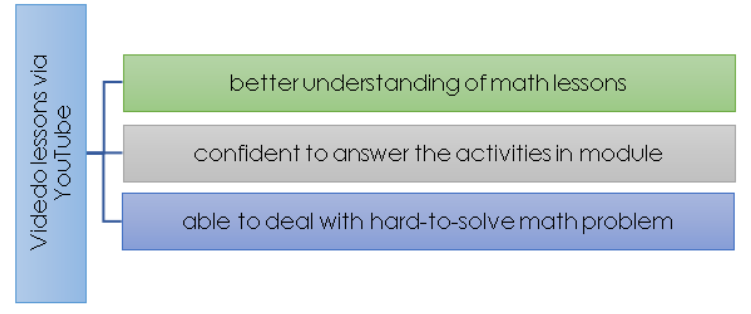

Figure 3. Effects of video lessons via YouTube

The statements above are supported by the words of the participants below:

"It is faster to understand each lesson because it is discussed properly through video. The explanation in the local language helps me to fully understand the lesson" - Participant 2

"It makes it easier for us to answer learning tasks because we understand them better through the video lessons via YouTube channel. The teacher explains well the lesson step-by-step." Participant 10

"Thanks to this YouTube channel, our learning has become faster, especially with difficult and complex lessons. I can answer difficult math problems in the module." - Participant 14

Figure 4 depicts the suggestions given by the students to improve the teacher-made video lessons uploaded in the YouTube channel Direct to the Point by DM. First, they suggested having regular uploading of video lessons to anticipate the new lesson, followed by activities. It means there should be a fixed day when the teacher will upload the video lesson since most of them were using data load to have an internet connection. They also suggested having more examples or illustrations from the video lessons with a loud and clear voice to catch each teacher's word. Finally, they suggested increasing the volume of sounds so that the voice is loud enough to hear while watching using smartphones.

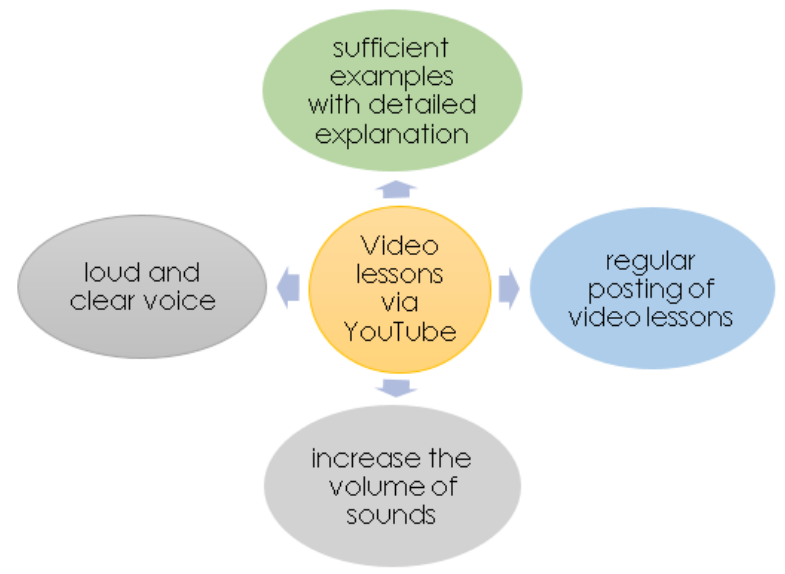

Figure 4. Students' suggestions to improve video lessons via YouTube

The statements above are supported by the words of the participants below:

"The audio can be amplified so that the video lessons can be better understood." - Participant 7 
"Continue to upload video lessons and provide activities at the end of the video for us to understand the math lesson. If possible, make it regular uploading." - Participant 12

"My suggestion is please make the explanation more detailed and complete so that we can get the right and definite answer for every query in the activity sheets." - Participants 19

\section{DISCUSSION}

The study has proven that teacher-made video lessons via YouTube channels help the students to understand mathematics lessons through watching conveniently and repeatedly. Seeing their teacher lecturing in the video motivates the students to consume the video and pay attention to the lectures. It means YouTube videos as supplementary instructional materials enhanced the students' learning experience in developing school learning competencies (Moghavvemi et al., 2018). Students tend to consume videos since these were related to the school subject that produces learning (Zhou et al., 2020). They enjoyed watching the videos just to gain competencies and apply them to do assigned activities. The teacher's explanation found in the video improved the understanding of the students on mathematics lessons (Muniyandy et al., 2015). This was shown in the performance of the student on the examination wherein an increment from the pretest to the posttest justified the increase in students' understanding supported by their qualitative responses in the survey and interview.

A Youtube channel may utilize as a platform that facilitates learning school subjects (Buzzetto-More, 2014; DeWitt et al., 2013), develops self-paced learning (Lee et al., 2017), and improves a better understanding of subject matter (Clifton \& Mann, 2011). The study has proven that YouTube as social media platform can be utilized as an educational delivery platform that empowers the students to learn at their own pace because they have control over their learning. YouTube can be used as a platform to deliver lectures (Subhi et al., 2020). Students can learn mathematics lessons conveniently, have a better understanding of the lesson, and be capable of dealing with complex mathematics problems. Hence, they love watching YouTube teachermade videos repeatedly to fully understand the mathematics lesson anytime as long as connected to the internet.

In the time of pandemic wherein face-to-face instruction is not allowed, YouTube can be used by the mathematics teachers to deliver content lessons to their students and make learning possible even at home. Students were able to understand mathematics concepts and gain competencies through watching video lessons since the teacher was explaining the content of the mathematics lesson that enhance students' learning (Tan \& Pearce, 2011). Students were confident to perform assigned tasks and solve mathematical problems since the mathematics lessons were well-explained by their teacher. Video lessons as interventions combined with modular learning produce an effective approach to students learning in a time of the pandemic (Bullo, 2021). Through watching video lessons, students were able to understand the lesson even without the teacher.

\section{CONCLUSIONS AND RECOMMENDATIONS}

The study's goal was to assess the use of the YouTube channel Direct to the Point by DM to deliver teacher-made video lessons.
Increased mean scores of students manifested the positive effect of the interventions since statistical significance was established using paired samples t-test and practical significance was placed using the effect size. Through watching video lessons, students learned more mathematics lessons and were able to develop mathematics competencies. They were confident enough to deal with the activities in the modules, even some of them were hard-to-solve problems. However, they suggested that the teacher have a clear and well-modulated voice in explaining the content from the video with enough examples in detailed explanation so that they have a deeper understanding of the mathematics concepts. Moreover, video lessons must be posted regularly so that the students anticipate watching habitually.

The study was limited to the four sections of Grade 7 in one school for two-month implementation period. It is recommended to have similar studies from other schools to assess the effectiveness of YouTube video lessons in mathematics. Hence, a longer implementation time for the next cycle of action research must be considered to sustain the students' interest in consuming video lessons. Moreover, the teacher may conduct a weekly poll to determine the students' insights regarding the video to make necessary adjustments. The voices of the students as consumers help a lot for the improvement of the interventions. Also, the teacher must secure that the video lessons were recorded in a well-lighted room with a high volume of sound since most of the students use smartphones to watch. In terms of content, sufficient examples must be included in the video lesson with detailed explanations to understand the lesson better.

Author contributions: All authors were involved in concept, design, collection of data, interpretation, writing, and critically revising the article. All authors approve final version of the article.

Funding: The authors received no financial support for the research and/or authorship of this article.

Acknowledgements: The researchers express their gratitude to the different entities that help them to conceptualize and make the action research possible despite the challenges, particularly, to San Pedro Relocation Center National High School - Main Campus for providing us an opportunity to grow and develop as professional educators who inspire others and continually serve the future generation; to Frederick G. Byrd Jr., Principal IV, for his permission, commitment, suggestions, and all-out support to conduct this study; to Marites M. Urcia, Head Teacher IV Mathematics, for her precious time and technical support upon completing action research. Her encouragement to conduct action research ignites the mathematics teachers' passion for thinking beyond the box and making a difference for a better teaching-learning process; to Analisa Rosa P. Librada and Lorenzo Y. Baldovino, for validating the research instruments used in this study; to all Grade 7 students who participate voluntarily to complete this research. Your presence and learning needs derive the teachers initiative to conduct action research to address the challenges brought by the new learning situation in the new normal.

Declaration of interest: Authors declare no competing interest.

Data availability: Data generated or analysed during this study are available from the authors on request.

\section{REFERENCES}

Benedict, L., \& Pence, H. E. (2012). Teaching chemistry using studentcreated videos and photoblogs accessed with smartphones and twodimensional barcodes. Journal of Chemical Education, 89(4), 492-496. https://doi.org/10.1021/ed2005399 
Bernardo, J. (2020). Modular learning most preferred parents: DepEd. ABS-CBN News. https://news.abs-cbn.com/news/07/30/20/ modular-learning-most-preferred-by-parentsdeped

Bokhove, C., \& Drijvers, P. (2012) Effects of a digital intervention on the development of algebraic expertise. Computers \& Education, 58(1), 197-208. https://doi.org/10.1016/j.compedu.2011.08.010

Broto, A. (2008). Statistics made simple (2nd ed.). National BookStore.

Bullo, M. (2021). Integration of video lessons to Grade-9 science learners amidst COVID-19 pandemic. International Journal of Research Studies in Education, 10(9), 67-75. https://doi.org/10.5861/ ijrse.2021.670

Buzzetto-More, N. A. (2014). An examination of undergraduate student's perceptions and predilections of the use of YouTube in the teaching and learning process. Interdisciplinary Journal of ELearning and Learning Objects, 10, 17-32. https://doi.org/10.28945/ 1965

Clark, K. P., Stearne, D. J., Walts, C. T., \& Miller, A. D. (2010). The longitudinal effects of resisted sprint training using weighted sleds vs. weighted vests. Journal of Strength and Conditioning Research, 24(12),3287-3295.https://doi.org/10.1519/JSC.0b013e3181b62c0a

Clifton, A., \& Mann, C. (2011). YouTube enhance student nurse learning? Nurse Education Today, 31(4), 311-313. https://doi.org/10.1016/j.nedt.2010.10.004

Copper, J. M., \& Semich, G. W. (2019). Professional development in the twenty-first century: YouTube teacher training and professional development. In M. Habib (Ed.), Advanced online education and training technologies (pp. 185-199). IGI Global. https://doi.org/10.4018/978-1-5225-7010-3.ch011

Dangle, Y. R. P., \& Sumaoang, J. (2020). The implementation of modular distance learning in the Philippine secondary public schools. In 3rd International Conference on Advanced Research in Teaching and Education (pp. 100-108). https://doi.org/10.33422/ 3rd.icate.2020.11.132

Dankel, S. J., Mouser, J. G., Mattocks, K. T., Counts, B. R., Jessee, M. B., Buckner, S. L., \& Loenneke, J. P. (2017). The widespread misuse of effect sizes. Journal of Science and Medicine in Sport, 20(5), 446-450. https://doi.org/10.1016/j.jsams.2016.10.003

de Villarreal E. S. S., Requena, B., \& Newton, R. U. (2010). Does plyometric training improve strength performance? A metaanalysis. Journal of Science Medicine Sport, 13(5), 513-522. https://doi.org/10.1016/j.jsams.2009.08.005

de Villarreal, E. S. S., Kellis, E., Kraemer, W. J, \& Izquierdo, M. (2009). Determining variables of plyometric training for improving vertical jump height performance: A meta-analysis. Journal of Strength and Conditioning Research, 23(2), 495-506. https://doi.org/10.1519/JSC.0b013e318196b7c6

Department of Education. (2020). Adoption of the basic education learning continuity plan for school year 2020-2021 in the light of the covid-19 public health emergency. https://www.deped.gov.ph/ wp-content/uploads/2020/06/DO_s2020_012.pdf

DeWitt, D., Alias, N., Siraj, S., Yaakub, M., Ayob, J., \& Ishak, R. (2013). The potential of Youtube for teaching and learning in the performing arts. Procedia - Social and Behavioral Sciences, 103,11181126. https://doi.org/10.1016/j.sbspro.2013.10.439
Farhan, R. N. (2019). Online discussion via Facebook Messenger: Impact on students' test performance of William Golding's "Lord of the Flies." International Journal of Innovative Technology and Exploring Engineering, 9(2), 4782-4787. https://doi.org/10.35940/ijitee. B6702.129219

Fraenkel, J., \& Wallen, N. (2010). How to design and evaluate research in education. McGraw-Hill Companies, Inc.

Given, L. (2008). The Sage encyclopedia of qualitative research methods. SAGE. https://doi.org/10.4135/9781412963909

Hansen, K. T., Croni, J. B., Pickeringm, S. L., \& Newton, M. (2011). Does cluster loading enhance lower body power development in preseason preparation of elite rugby union players? Journal of Strength and Conditioning Research, 25(8), 2118-2126. https://doi.org/10.1519/JSC.0b013e318220b6a3

Hong, J. C., Hwang, M. Y., Szeto, E., Tsai, C. R., Kuo, Y.-C., \& Hsu, W. Y. (2016). Internet cognitive failure relevant to self-efficacy, learning interest, and satisfaction with social media learning. Computers in Human Behavior, 55(A), 214-222. https://doi.org/10.1016/j.chb.2015.09.010

June, S., Yaacob, A., \& Kheng, Y. (2014). Assessing the use of YouTube videos and interactive activities as a critical thinking stimulator for tertiary students: An action research. International Educational Studies, 7(8), 56-67. https://doi.org/10.5539/ies.v7n8p56

Jung, I., \& Lee, Y. (2015). YouTube acceptance by university educators and students: A crosscultural perspective. Innovations in Education and Teaching International, 52(3), 243-253. https://doi.org/10.1080/ 14703297.2013.805986

Lee, C. S., Osop, H., Goh, D. H., \& Kelni, G. (2017). Making sense of comments on YouTube educational videos: A self-directed learning perspective. Online Information Review, 41(5), 611-625. https://doi.org/10.1108/OIR-09-2016-0274

Lydersen, S. (2020). Mean and standard deviation or median and quartiles? The Journal of the Norwegian Medical Association, 140(9). https://doi.org/10.4045/tidsskr.20.0032

Moghavvemi, S., Sulaiman, A., Jaafar, N. I., \& Kasem, N. (2018). Social media as a complementary learning tool for teaching and learning: the case of YouTube. The International Journal of Management Education, 16(1), 37-42. https://doi.org/10.1016/j.ijme.2017.12.001

Muniyandy, S., Khuenyen, N., Yap, C. G., Shogo, M., My, N. A., Chowdhury, M. E. H., \& Musa, A. F. (2015). Influence of YouTube videos on the learning of tablet- and capsule-formulation by Malaysian pharmacy students: A pilot study. Pharmacy Education, 15(1), 248-251. https://pharmacyeducation.fip.org/pharmacy education/article/view/396/343

Okeniyi, J. O., Okeniyi, E. T., \& Atayero, A. A. (2015). Programming development of Kolmogorov-Smirnov goodness-of-fit testing of data normality as a Microsoft Excel ${ }^{\circledR}$ library function. Journal of Software \& Systems Development, 2015(2015), Article ID 238409. https://doi.org/10.5171/2015.238409

Pallant, J. (2007). SPSS Survival manual: A step by step to data analysis using SPSS for Windows (Version 15). Allen and Unwin.

Ranga, J. (2017). Customized videos on a YouTube channel: A beyond the classroom teaching and learning platform for General Chemistry courses. Journal of Chemical Education, 94(7), 867-872. https://doi.org/10.1021/acs.jchemed.6b00774 
Sharma, L. R. (2021). Analysis of difficulty index, discrimination index and distractor efficiency of multiple choice questions of speech sounds of English. International Research Journal of Makawanpur Multiple Campus, 2(1), 15-28. https://doi.org/10.3126/irjmmc.v2i1. 35126

Soong, T. T. (2004). Fundamentals of probability and statistics for engineers. John Wiley \& Sons, Ltd.

Subhi, M. A., Nurjanah, N., Kosasih, U., \& Rahman, S. A. (2020). Design of distance lectures in mathematics education with the utilization of the integration of Zoom and YouTube application. Journal of Physics: Conference Series 1663, 1-7. https://doi.org/ 10.1088/1742-6596/1663/1/012058

Tan, E., \& Pearce, N. (2011). Open education videos in the classroom: Exploring the opportunities and barriers to the use of YouTube in teaching introductory sociology. Research in Learning Technology, 19(1), 125-133. https://doi.org/10.3402/rlt.v19i3.7783

Taylor, L., \& Parsons, J. (2011). Improving student engagement. Current Issues in Education, 14(1), 1-32. http://cie.asu.edu/ojs/index.php/ cieatasu/article/viewFile/745/162
Terlumun, I. T., Appollm, Y. I., Ibrahim, F. J., Mamman, F. S., Yusuf, A. K., \& Ibrahim, A. H. (2018). Determining the effectiveness of YouTube videos in teaching and learning with Mozdeh algorithm. International Journal of Education and Evaluation,4(4), 100-110. https://iiardpub.org/get/IJEE/VOL.\%204\%20NO.\%204\%202018/ DETERMINING\%20THE.pdf

Vural, O. F. (2013). The impact of a question-embedded video-based learning tool on elearning. Educational Sciences: Theory \& Practice, 13(2), 1315-1323. https://files.eric.ed.gov/fulltext/EJ1017292.pdf

Williams, A. J., \& Pence, H. E. (2011). Smartphones, a powerful tool in the chemistry classroom. Journal of Chemical Education, 88(6), 683686. https://doi.org/10.1021/ed200029p

Zhou, Q., Lee, C., Sin, S., Lin, S., Hu, H., \& Ismail, M. F. (2020). Understanding the use of YouTube as a learning resource: A social cognitive perspective. Aslib Journal of Information Management, 72(3), 339-359. https://doi.org/10.1108/AJIM-10-2019-0290 